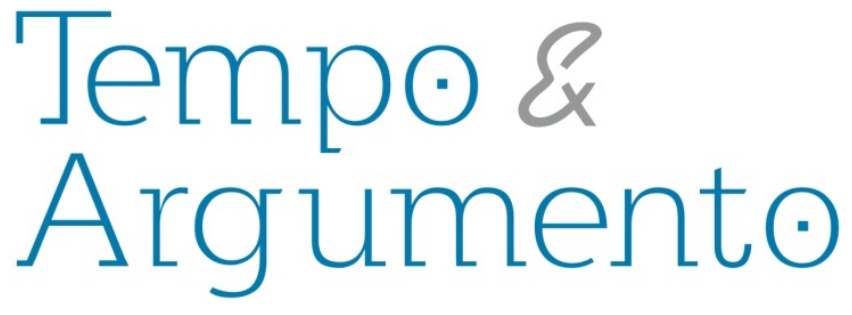

\title{
Por uma antropologia das emoções do nazismo
}

\section{Resenha da obra:}

INGRAO, Christian. Crer e destruir: os intelectuais na máquina de guerra da SS nazista.

Rio de Janeiro: Zahar, 2015.

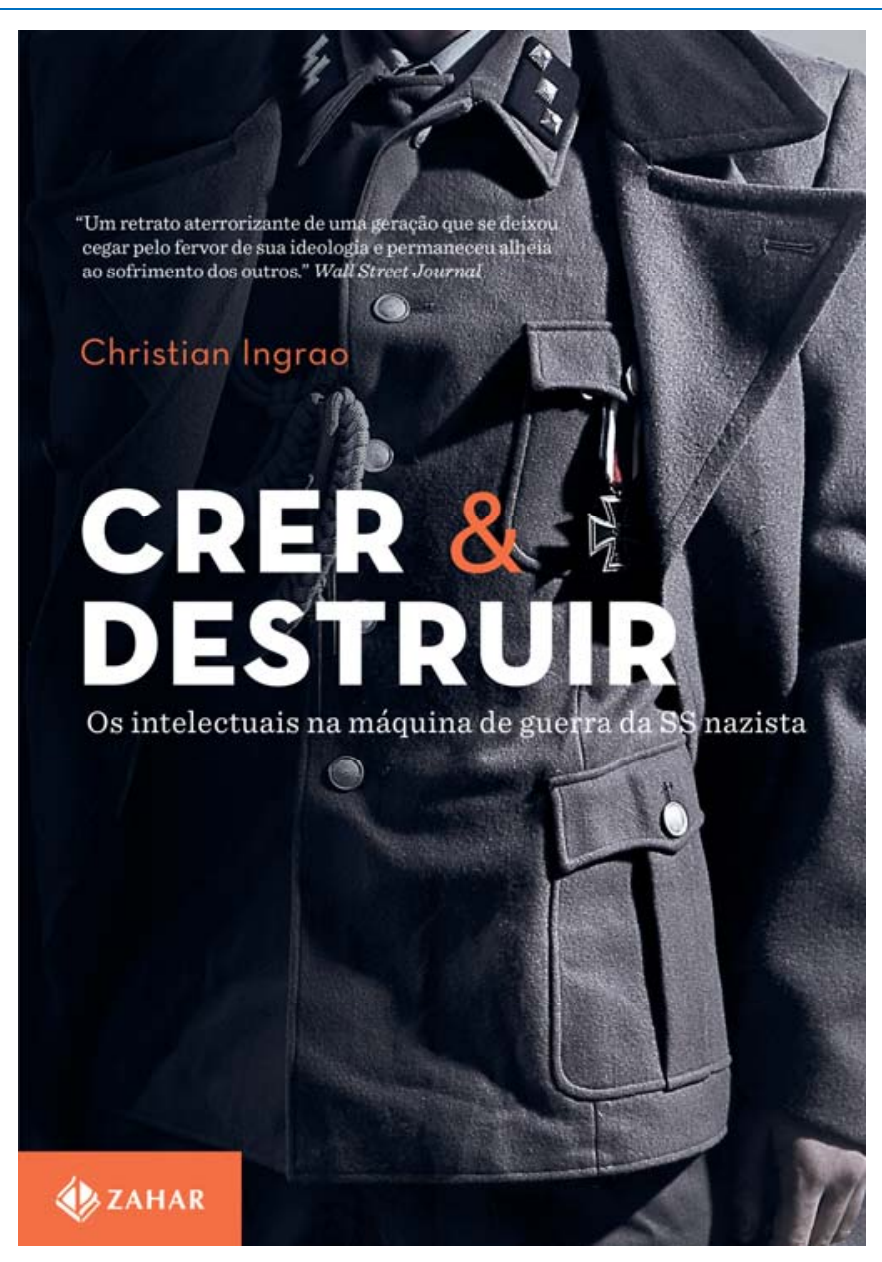

\section{Autora da resenha}

Franciele Becher

Mestra em História pela Universidade Federal do Rio Grande Sul (UFRGS). Brasil franciele.becher@gmail.com

\section{Para citar esta resenha:}

INGRAO, Christian. Crer e destruir: os intelectuais na máquina de guerra da SS nazista. Rio de Janeiro: Zahar, 2015. Resenha de: BECHER, Franciele. Por uma antropologia das emoções do nazismo. Revista Tempo e Argumento, Florianópolis, v. 9, n. 21, p. 482 - 487. maio/ago. 2017. 
A proposta de fazer uma "história das emoções" do nazismo pode parecer, em um primeiro momento, desconfortável. E isso ocorre, sobretudo, porque a representação mais recorrente do nacional-socialismo sempre liga os seus atores a ações brutais, cegas e fanáticas. A imagem cristalizada do nazismo enquanto um caso de violência definitiva muitas vezes leva os historiadores a definirem categorias conceituais imprecisas ou genéricas, já adaptadas ao discurso que normalmente é utilizado no estudo dos regimes autoritários.

O livro de Christian Ingrao, historiador francês ligado ao Centre national de la recherche scientifique (CNRS) e antigo diretor do Institut d'Histoire du Temps Présent (IHTP), procura traçar os itinerários profissionais e militantes de cerca de 80 intelectuais e acadêmicos que fizeram suas carreiras em órgãos de repressão ligados à Ordem Negra, a SS, ao Serviço de Segurança (SD), ou ao Gabinete Central de Segurança do Reich (RSHA). Em comum, todos os sujeitos analisados têm a participação nas missões de repressão, combate e ocupação do Leste europeu, seja nas campanhas da Polônia ou da União Soviética, ao longo da Segunda Guerra Mundial. Muitos deles estiveram implicados diretamente nas matanças efetuadas pelas forças-tarefa dos Einsatzgruppen, e nas medidas implantadas na organização do genocídio de milhões de judeus e outras vítimas eslavas.

Através dos pressupostos teóricos da antropologia social das emoções e da história cultural, e utilizando uma vasta gama de fontes e arquivos, que inclui narrativas de vida dos akademiker, suas trajetórias profissionais, documentações dos órgãos dos quais faziam parte e seus depoimentos nos julgamentos do pós-guerra, o autor consegue traçar um panorama competente sobre as representações de mundo desses intelectuais. Fugindo de uma análise funcionalista das instituições e de sua incidência sobre os comportamentos, Ingrao tece o esboço sobre a forma como esses sujeitos conseguiram aliar seu rigor científico às exigências da militância nazista, criando grades de leitura do mundo e discursos de legitimação que deram suporte aos massacres e ao genocídio.

Fruto da tese de doutorado do autor, escrita entre 1997 e 2001, na Universidade de Amiens ("Les intellectuels du service de renseignement de la S.S, 1900-1945 "), o livro toma como ponto de partida a apreensão do nazismo enquanto um sistema de crenças que 
combina práticas e discursos frutos de políticas públicas e institucionais, mas que também são percorridos por uma gama de emoções que vão da angústia à utopia, passando pelo ódio, crueldade e desespero, e que não podem ser apreendidas dentro dos paradigmas clássicos da política e da sociologia. Ingrao procura compreender em que medida as experiências vividas por esses intelectuais foram capazes de modelar seu sistema de representações, criando eixos de consentimento que os levariam, no futuro, a legitimar a violência extrema.

Partindo da herança de historiadores da Primeira Guerra Mundial, sobretudo do seu orientador de tese, Stéphane Audoin-Rouzeau, que trabalhou com as experiências infantis ligadas ao conflito, o autor procura apreender a militância nazista desses intelectuais como uma reação à experiência matricial de 1914-1918, cuja coerência entre discursos e práticas se encarnou em suas trajetórias e carreiras. Em suma, procura compreender como esses homens fizeram para crer e, por consequência, destruir. Sujeito de pesquisa inquietante, sobretudo porque confronta o fato de que setores da alta excelência acadêmica alemã atuaram diretamente em um dos mais atrozes regimes autoritários, servindo-se, inclusive, das Ciências Humanas e, em particular, da História, como legitimadoras desses processos.

O livro é organizado em três partes: na primeira delas, Ingrao traz três capítulos sobre a experiência matricial da Primeira Guerra Mundial, e de como toda a cultura do “mundo de inimigos" e da crença no papel defensivo da Alemanha no conflito, mesmo que silenciada pelos akademiker, influenciou suas trajetórias e seus imaginários. Além disso, estabelece um panorama das instituições e dos saberes acadêmicos e militantes construídos pelos futuros oficiais entre os anos 1920 e 1930, quando turbulentas disputas políticas influenciaram nos seus sentimentos de angústia, e interferiram em suas escolhas e ambições científicas e, claro, nos seus engajamentos políticos dos anos seguintes.

Formando-se como advogados, economistas, geógrafos, historiadores ou linguistas no pós-guerra, muitos deles com formações universitárias multidisciplinares com alto desempenho acadêmico, esses jovens, vindos em sua maior parte das classes médias alemãs, encontraram na SS um organismo elitista que se distanciava das "hordas" do partido de massa, ou da atuação pragmática das tropas de assalto (SA). Através de 
diversos ritmos e itinerários de militância, entraram no jogo dos mecanismos institucionais da burocracia nazista, contribuindo para sua justificação científica e ideológica e, ao mesmo tempo, reforçando suas próprias leituras de mundo, profundamente marcadas por suas experiências de vida.

A segunda parte do livro, consagrada à internalização das crenças, à adesão ao nazismo e ao engajamento intelectual e ideológico dos jovens acadêmicos, analisa as fundamentações do dogma nacional-socialista em sua profunda inspiração de refundação da Alemanha no aspecto sociobiológico e racial. Estudando a grade da leitura sociológica dos discursos dos intelectuais SS, Ingrao demonstra como a ideologia racial incidiu na própria reformulação da história alemã, transformando-a em uma série de lutas, confrontos e combates identitários, todos marcados pelo selo da etnicidade. Problematiza como a História e outras disciplinas se tornaram ciências combatentes de legitimação das crenças nazistas, justificando a guerra que estava por vir como um último combate pela salvação providencial do Império Alemão.

Ingrao foge constantemente da armadilha fácil de usar conceitos genéricos e imprecisos como o do "oportunismo" da ascensão hierárquica dentro da estrutura do Reich. Demonstra, no caso dos intelectuais SS, que havia inclusive uma tentativa institucional de frear esses interesses para proteger o ativismo e a militância. O processo de politização dos saberes dos akademiker aconteceu paralelamente à sua própria construção, e foi fortalecido com a criação de instituições como o SD e o RSHA, quando puderam aliar seu rigor científico às exigências da militância, imprimindo suas marcas nos serviços em que atuaram e participando de forma determinante na organização da repressão.

Por fim, na terceira parte da obra, Ingrao volta seus olhos à experiência de guerra no Leste europeu, onde as crenças e o fervor nazista foram empregados na legitimação da violência extrema e do genocídio. Os últimos cinco capítulos dão conta do imaginário construído em torno do novo "mundo de inimigos" eslavos, analisando a ritualística da violência, e as estratégias empregadas para colocar em prática os massacres. Além disso, finaliza avaliando as posturas dos intelectuais SS frente à derrota iminente, assim como suas estratégias de negação e reelaboração da memória nos julgamentos do pós-guerra. 
Para os nazistas, o "Leste" simbolizava uma tábula rasa na qual a germanidade poderia se modelar, ocupando o espaço de povos vistos como bárbaros e inferiores. Dentro da retórica do "sangue e solo", a experiência de guerra inaugurada com a invasão da Polônia em 1939, e intensificada com o ataque à União Soviética em 1941, se transformou em uma luta total contra o inimigo "judeu-bolchevique”. O "imaginário de cruzada", uma mescla entre fervor, utopia e guerra, forneceu a moldura justificativa para a violência que os soldados deveriam empregar, dentro de um discurso ansiogênico que instilava os comportamentos coletivos à matança.

Nesse contexto, a prática genocida se tornou uma condição da germanização, o fim último da utopia milenarista do nazismo. Representado como uma ação defensiva (pois era legítimo se defender dos agentes de destruição da germanidade, argumento semelhante ao usado pelas elites alemãs para justificar o conflito de 1914.), e visto sob a ótica da deploração (matar é um trabalho asqueroso, mas necessário), o genocídio ocorreu em meio a um investimento afetivo real dos intelectuais SS. A leitura nazista dos acontecimentos, elaborada, interiorizada e difundida pelos akademiker, constituiu então o cerne do mecanismo de radicalização e de consentimento aos massacres.

Por trás dos imperativos de produtividade e exaustividade que foram usados para colocar em prática os assassinatos em massa, estavam preocupações com um imaginário asséptico que pouparia psicologicamente os atores do massacre, limitando o seu efeito desestruturante e traumático. O estabelecimento de hierarquias na matança, e o próprio gestual da violência, refletiam o sistema cultural em que essas práticas foram forjadas. Angústia, deploração, repulsa, ódio e gozo se confundiram nos discursos e atitudes dos que atuaram no Leste, experiência que funcionava como um "rito iniciático" para que os oficiais provassem seu grau de interiorização da crença nazista. Porém, apesar da dimensão traumática exteriorizada nos comportamentos de vários oficiais, nunca houve ruptura com o consentimento à matança, e isso se deu em função do acompanhamento do discursivo legitimador, da sistematização dos gestos e dos processos de adaptação empregados.

Face à derrota iminente, os intelectuais SS apresentaram diversas estratégias de escape, em uma distorção crescente entre os comportamentos e a realidade do front, 
mesmo que possam ser detectados indícios da escalada de suas angústias. Após 1945, boa parte dos akademiker passou por tribunais e comissões de “desnazificação", em que procuraram realizar uma gestão da memória de guerra e da sua militância, usando diferentes estratégias de negação dos seus crimes ao longo dos julgamentos. A própria tese da "obediência incondicional" dentro da hierarquia nazista, utilizada pelos historiadores durante muito tempo para analisar os comportamentos dos atores do genocídio, é decodificada enquanto um desses artifícios de despistamento utilizados intencionalmente pelos intelectuais julgados.

Publicado originalmente em 2010, pela Arthème Fayard, sob o título Croire et détruire. Les intellectuels dans la machine de guerre SS, a obra de Christian Ingrao demonstra que a interiorização do sistema de crenças nazista era muito mais um caso de fervor do que de cálculo político e militante. Mesmo que o livro não seja de fácil leitura (em função, sobretudo, da temática delicada, mas também em razão de certos aspectos da tradução brasileira), o autor guia habilmente o leitor pela intrincada burocracia dos órgãos nazistas, tecendo uma narrativa que foge de armadilhas conceituais psicologizantes ou abstratas. Apoiado por uma extensa bibliografia sobre o assunto em várias línguas, e por indicações de fontes impressas e de fundos arquivísticos, sua obra traz possibilidades teóricas de problematizar os diferentes níveis de instrumentalização dos saberes, o papel dos intelectuais, da educação e, particularmente, da ciência histórica na legitimação da violência e dos regimes políticos autoritários. 